\title{
Resenha: Elegía Apu Inka Atawallpaman. Primer documento de la resistencia Inka (siglo XVI)
}

Roseli Barros Cunha*

Gonzales, O. Elegía Apu Inka Atawallpaman. Primer documento de la resistencia Inka (siglo XVI). Lima: Grupo Pakarina, 2014.

Em Elegía Apu Inka Atawallpaman, Odi Gonzales, peruano radicado nos Estados Unidos e professor da Universidade de Nova lorque, apresenta uma proposta de retradução do poema "Apu Inka Atawallpaman", sobre a morte do imperador inca Ataualpa; cotejos entre transcrições do poema na língua quéchua e entre traduções para o castelhano; além de um amplo aparato de elementos paratextuais que colaboram com a hipótese lançada pelo pesquisador a respeito da autoria e provável data de escritura daquele que considera o primeiro documento de resistência inca.

A obra tem a seguinte divisão: "Comunidad de hablantes", primeiro capítulo; segundo, "Harina de otro costal"; terceiro capítulo, "Texto y contexto"; quarto e quinto, "Un cantar de largo aliento" e "Laguna mental", respectivamente. Há também os "Anexos"; um prólogo, "Un libro tan esperado como necesario", assinado pela pesquisadora Mercedes López-Baralt e ainda, no início, a seção "J usticia poética", na qual o autor comenta brevemente as motivações acadêmicas e pessoais que o levaram a empreender a tradução e a escritura do livro.

${ }^{*}$ Doutora pela FFLCH/ USP (2005), professora-adj unto da DLE/ UFC. E-mail: roselibc@gmail.com 
CUnHA, R. B. - Resenha: Elegía Apu Inka Atawall paman. Primer documento de la resistencia Inka (siglo XVI)

$\mathrm{Na}$ introdução ao primeiro capítulo, encontramos espelhadas a transcrição do poema em quéchua e a tradução ao castelhano, ambas realizadas pelo autor. Nos "Anexos", a transcrição e retradução de Gonzales podem ser contrastadas com as mais antigas, de José Mario Benigno Farfán, de 1942, publicadas no suplemento especial que ele compilou para a Revista del Instituto de Antropología, da Universidade Nacional de Tucumán, Argentina, e com as de José María Arguedas, de 1955, cujo subtítulo é "elegia quéchua anônima".

Segue nesse capítulo um estudo histórico do percurso do poema. Ele teria chegado ao conhecimento de Farfán por meio de um harpista de Cusco, que, por sua vez, o teria subtraído de um livro de cantos do músico e compositor Cosme Ticona, recompilador da obra em quéchua no início do século XX. O autor também faz referência a outras traduções do poema, como a de López-Baralt e Donald Solá (1980), com sua primeira versão para o inglês, ou ainda aos fragmentos do poema alternados ao discurso narrativo no romance El jinete insomne (1978), de Manuel Scorza.

Dessas considerações Gonzales passa a recuperar o momento de escritura do poema e sua autoria. Comenta que Arguedas acreditava que o autor da poesia teria conhecimento histórico de fatos posteriores à queda do império inca. Além disso, pelo estilo e léxico, considerava que o poema teria sido escrito no final do século XVI ou no XVII (pp. 38). O autor contrapõe outro ponto de vista, o do pesquisador Jesús Jara, para quem o poema pertenceria ao ciclo pré-colonial, quase imediatamente à morte do imperador, uma vez que não encontrava nele influência da poesia espanhola, e sim características do que entendia como "poesia tawantinsuyana". Essa hipótese é refutada por Gonzales, para quem, devido a sua natureza oral, não haveria como recuperar tais formas da poesia pré-hispânica quéchua. O autor ainda dá voz a outras interpretações, como a de López-Baralt (2005), que crê que a obra foi composta entre o final do século XVIII ou início do XIX; J ulio Ortega (2003), que indica 0 século XVIII; e César Itier (2000), para quem a composição não é anterior ao XIX. 
CUnHA, R. B. - Resenha: Elegía Apu Inka Atawallpaman. Primer documento de la resistencia Inka (siglo XVI)

Ao procurar resgatar a autoria da obra, Gonzales reconstitui o contexto histórico que é tema do poema. Ele faz alusão à morte do rei Ataualpa, abatido pelos espanhóis depois de o império inca enfraquecer-se por uma guerra fratricida. Mas não apenas a esse fato. A "Elegía" teria sido escrita nos "últimos 50 anos do século XVI" (pp. 43), posteriormente à morte de outro inca importante, Tupaq Amaru I, em 1572: "a morte de Atawallpa constitui a primeira morte do Inka como líder do mundo quéchua, a morte de Tupaq Amaru, a segunda e definitiva aniquilação da estirpe e o colapso do império inca" (pp. 48), constatação que leva o autor a considerar a obra como 0 "primeiro documento da resistência inca".

Gonzales segue apresentando elementos para comprovar sua hipótese mediante uma ampla bibliografia comentada, assimilada ou refutada, mas também e, principalmente, construída por meio do que ele conclui a partir de sua transcrição e tradução do texto do quéchua para o castel hano. Os capítulos que as seguem são elementos paratextuais que colaboram com sua proposta de retradução.

No segundo capítulo, o autor, além de tratar de outra obra supostamente recolhida por Lara, a peça dramática Tragedia del fin de Atawallpa, realiza uma breve análise temática entre ela e a "Elegía"; coteja a transcrição quéchua realizada por Farfán (1942) e a de Lara (1947), na qual, segundo ele, há constantes modificações e algumas adaptações da variante do quéchua cusquenho à do quéchua boliviano e, ainda, a de Arguedas (1955).

No terceiro capítulo, Gonzales relaciona a obra Instrucción del Inca Don Diego de Castro Titu Cusi Yupanqui al licenciado don Lope García de Castro, crônica ditada por Titu Cusi Yupanqui e registrada em espanhol, em 1570, com a "Elegía". Não quer, com isso, dizer que o autor de uma conhecesse a outra, mas reitera que ambas são "documentos de uma mesma época, de um mesmo sentimento, regidos pela memória oral, e que contêm, portanto, evidentes coincidências" (pp. 92).

Gonzales trata também do texto e imagem registrados no manuscrito em quéchua Primer Nueva Coronica y Buen Gobierno, de 1615, do cronista Felipe 
CunHA, R. B. - Resenha: El egía Apu Inka Atawallpaman. Primer documento de la resistencia Inka (siglo XVI)

Guaman Poma, e tece considerações sobre a diferente tradução apresentada no Sitio de Guaman Poma e a que ele entende como construída pelo autor, um indivíduo bilíngue principiante, no fragmentado texto em quéchua.

Nesse capítulo, Gonzales refere-se ao aspecto formal do poema como uma confluência das tradições espanholas, tal como assinalaram Arguedas (1957) e López-Baralt (2005), e da tradição indígena, para uma vez mais defender sua tese de que 0 autor seria um mestiço aculturado que poderia conhecer inclusive as Coplas a la muerte de su padre, do poeta espanhol do século XVI, J orge Manrique (pp. 106-107).

No quarto capítulo, Gonzales coteja outras traduções com a que propõe. Para isso, faz um estudo sobre as duas traduções de Farfán (1942; 1947), realizadas a partir de apenas uma transcrição do quéchua. Segundo o autor, o objetivo expresso desse primeiro tradutor teria sido o de realizar uma "tradução mais literal", "somente em poucos casos atendendo mais à expressão do pensamento que da forma, quando não se podia encontrar uma dicção castelhana correspondente" (pp. 114).

Também coteja sua tradução com a de Teodoro Meneses, de 1957; a de Mercedes López-Baralt e Solá, de 1980, e ainda a de Arguedas, de 1955, que, segundo Gonzales, tinha como língua materna outra variante do quéchua, o chanka, e de quem comenta que algumas decisões tomadas para manter uma "extrema fidelidade" ao texto na língua indígena levam a uma "literalidade restritiva" (pp. 121), sem que isso desmereça seu valor. 0 autor justifica que as decisões tomadas por ele estão apoiadas em sua experiência como falante do quéchua cusquenho, o que já havia comentado na seção "J usticia Poética", onde informa ter nascido em Calca, Cusco, mesma região onde se recompilou o poema (pp. 9). Ao longo do capítulo, num estudo minucioso e didático, mostra espelhadamente as opções dos demais tradutores e as que ele produziu.

0 autor constrói, por meio da retradução e dos paratextos que apresenta, a comprovação de suas hipóteses sobre datação e autoria do poema, que muitas vezes contraria as hipóteses e opções tomadas por outros tradutores e estudiosos, como, por exemplo, em relação ao que sustenta López-Baralt sobre 
CunHA, R. B. - Resenha: Elegía Apu Inka Atawallpaman. Primer documento de la resistencia Inka (siglo XVI)

o texto e imagens de Guaman Poma e a crônica sobre a morte de Ataualpa apresentadas em Historia general del Perú terem sido "embriões" da "Elegía" (pp. 132).

Finalmente, no último capítulo, o autor promove, ainda que brevemente, um estudo sobre a intertextualidade da "Elegía" com outras obras que tratam do tema da morte do rei inca, tais como o livro de poemas Taki parwa, de Killu Warak'a, pseudônimo de Andrés Alencastre Gutiérrez, de 1952, e os poemas de Katatay, escritos por Arguedas entre 1962 e 1969, nos quais Gonzales encontra elementos da tradição oral também presentes na "Elegía". Comenta ainda a adaptação do tema da morte de Ataualpa para outras artes, tais como o documentário Llamellin y su fiesta patronal (2007), realizada pelo cineasta Mitchell Tepliski; o álbum Apurimac, (1985), da banda alemã de new age "Cusco", que inclui a canção "Atahualpa, the last Inca". Dentre essas retraduções, vale a pena destacar a pintura a óleo de Luis Montero, intitulada "Los funerales de Atahualpa", de 1867 (capa desta edição bem cuidada da editora peruana Pakarina), e a releitura contemporânea do artista plástico Marcel Velaochaga, em 2005, na qual em colagem realizada sobre o quadro de Montero insere referências a pessoas da atualidade, tais como o líder do movimento guerrilheiro "Sendero Luminoso" Abimael Guzmán, Che Guevara e o papa Bento XVI.

Enfim, o trabalho de Odi Gonzales é de grande interesse para estudiosos da tradução e de outras áreas que se debrucem sobre questões latinoamericanas e, mais especificamente, andinas. Além de um acurado trabalho de cotejo de traduções anteriores à sua, proporciona ao leitor uma retradução comentada e um amplo apoio paratextual da época de recolhimento do poema oral aos trabalhos de retraduções posteriores. Podemos valer-nos das palavras da pesquisadora da Universidade de Porto Rico Mercedes López-Baralt, que no prólogo à obra enaltece a pesquisa desenvolvida pelo autor e sua grande capacidade como tradutor, uma vez que, além de poeta, apresenta-nos a obra a partir de sua "própria experiência vital andina". 